\title{
Iron Deficiency in the Rat: Effects on Energy Metabolism in Brown Adipose Tissue
}

\author{
BRUCE MACKLER, RICHARD PERSON, AND RICHARD GRACE \\ Department of Pediatrics and the Child Development and Mental Retardation Center, University of Washington, \\ Seattle, Washington 98195
}

\begin{abstract}
Mitochondria were prepared from the brown adipose tissue of control rats and animals made iron deficient by means of a low iron diet. The specific activities of the mitochondrial electron transport system (NADH, succinate and $\alpha$-glycerophosphate oxidase activities) were markedly and significantly reduced in preparations of brown adipose tissue from the iron-deficient rats as compared with preparations from the control animals. In contrast, concentrations of the cytochrome pigments $a+a_{3}$, and $c+c_{1}$ were normal and cytochrome $b$ was slightly reduced $(18 \%)$ in the mitochondrial preparations from the iron-deficient animals. Treatment of the iron-deficient animals with triiodothyronine significantly increased the amount of brown fat present per kilogram of body weight in both control and iron-deficient rats, but did not significantly affect the specific activities of the mitochondrial electron transport system. (Pediatr Res 19: 989-991, 1985)
\end{abstract}

Abbreviations

T3, triiodothyronine

T4, thyroxine

Dillman et al. $(1,2)$ have shown that cold-induced nonshivering thermogenesis was reduced in iron-deficient rats despite elevated levels of catecholamines. Treatment of the iron-deficient rats with $\mathrm{T} 3$, but not $\mathrm{T} 4$, appeared to partially correct the defective thermoregulation and suggested that conversion of $\mathrm{T} 4$ to T3 was impaired in the animals. More recently, however, studies by Beard et al. $(3,4)$ suggest that anemia may play an important role in the cold sensitivity of iron deficiency in the rat.

Previously studies on nonshivering thermogenesis in coldacclimated rats have shown that a major proportion of heat production occurs in the brown fat (5), and Himms-Hagen and Desautels (6) have described a mitochondrial defect in the brown fat of the obese (ob/ob) mouse that may explain the reduced cold-induced thermogenesis present in the animals. The present work was, therefore, undertaken to study the effects of iron deficiency and treatment with T3 on mitochondrial function in brown fat since the enzyme systems (mitochondrial electron transport systems) active in energy and heat production contain both heme and nonheme iron components which are essential for enzymatic catalysis.

Received February 20, 1985; accepted May 6, 1985.

Correspondence Bruce Mackler, M.D., Department of Pediatrics, RD-20, University of Washington, Seattle, WA 98195

Supported in part by Grants HD 15915, GM 23006, and HD 02274 from the National Institutes of Health.

\section{MATERIALS AND METHODS}

Male Sprague-Dawley rats were obtained at 4 wk of age, 1 wk after weaning. Rats to be made iron deficient were given a low iron diet, prepared in our laboratory as described by ICN Nutritional Biochemicals, Cleveland, $\mathrm{OH}$, that contained $10 \mathrm{mg}$ iron/ $\mathrm{kg}$. After 1 month on this diet, the hemoglobin concentration of those animals receiving it was determined and studies were performed only on rats with blood $\mathrm{Hb}$ concentrations of less than $7 \mathrm{~g} / 100 \mathrm{ml}$. The control groups were fed the low iron diet during the experimental period, but received weekly intraperitoneal injections of $5 \mathrm{mg}$ of iron in the form of iron dextran (Imferon, Merrell-National Labs, Cincinnati, OH). All animals were allowed food and water ad libitum. One group of irondeficient rats and a group of control rats received daily intraperitoneal injections of $1 \mu \mathrm{g}$ of T3 [a pharmacological dose as described by Dillman et al. $(1,2)$ ] for 10 days before the experiments were performed.

The rats were sacrificed by cervical dislocation and the interscapular brown adipose tissue was quickly removed and weighed. Mitochondria were prepared from the adipose tissue as described by Skala et al. (7), with the exception that a solution of $0.30 \mathrm{M}$ sucrose and $0.02 \mathrm{M}$ Tris ( $\mathrm{pH} 7.5$ ) was used instead of a $0.25 \mathrm{M}$ solution of sucrose.

Difference spectra (dithionite reduced minus oxidized) of the cytochromes of the mitochondrial respiratory chain were determined by means of a sensitive wavelength-scanning Aminco DW-2 spectrophotometer at $25^{\circ} \mathrm{C}$ and the concentrations of the cytochromes were calculated by use of the following millimolar extinction coefficients: cytochrome $a \pm a_{3}(605-630 \mathrm{~nm}), 24.0$ (8); cytochrome $c+c_{1}(550-540 \mathrm{~nm}), 19.1$ (9); cytochrome $b$ (562-575 nm), $20.0(10)$.

$\mathrm{NADH}$, succinic and $\alpha$-glycerophosphate oxidase activites were determined polarographically in the mitochondrial preparations at $25^{\circ} \mathrm{C}$ with a Clark oxygen electrode (Yellow Springs Instrument Co., Yellow Springs, $\mathrm{OH}$ ) fitted to a closed glass thermostated chamber of $1.6 \mathrm{ml}$ capacity (Gilson Instrument Co., Madison, WI). Before assay, the preparations of mitochondria were homogenized at top speed for $5 \mathrm{~min}$ in a motor driven Teflon-glass homogenizer maintained at $5^{\circ} \mathrm{C}$ to ensure breakage of the mitochondria in order to obtain maximum enzymatic activities. Assay mixtures ( $\mathrm{pH} 7.5$ ) contained $40 \mu \mathrm{mol}$ of substrate (NADH, succinate or $\alpha$-glycerophosphate), $0.2 \mathrm{ml}$ of 0.2 $\mathrm{M}$ potassium phosphate, and $0.02 \mathrm{ml}$ of a $1 \%$ solution of cytochrome $c$ in a final volume of $1.6 \mathrm{ml}$. In control experiments it was determined that all activities (with added cytochrome $c$ present) were completely inhibited by addition of $23 \mu \mathrm{g}$ of antimycin $\mathrm{A}$.

Protein was determined by the method of Lowry et al. (11). $\mathrm{Hb}$ was determined as cyanmethemoglobin with standards employed for calibration (Hycel, Inc., Houston, TX). Statistical analyses were performed by standard methods of one-way analysis of variance for two independant samples as described by 
Snedecor and Cochran (12). NADH, cytochrome $c$ type VI, $\alpha$ glycerophosphate, Tris, and succinate were obtained from Sigma Chemical Co, St. Louis, MO. Antimycin A was a gift from Ayerst Laboratories, New York, NY.

\section{RESULTS AND DISCUSSION}

Mitochondrial preparations isolated from brown adipose tissue of control and iron-deficient rats were studied to determine the effects of iron deficiency on the enzymatic activities and the concentrations of the various cytochrome pigments associated with the terminal electron transport systems that generate the energy and heat produced in brown fat. As shown in Table 1, $\mathrm{Hb}$ concentrations were markedly reduced in the iron deficient rats and the activities of the electron transport enzymes (NADH, succinate, and $\alpha$-glycerophosphate oxidases) were markedly (more than 50\%) and significantly ( $p<0.01$ for all activities) reduced in the preparations from the iron-deficient animals. However, as described in Table 2, levels of cytochromes $a+a_{3}$ and $c+c_{1}$ were unaffected and concentrations of cytochrome $b$ were only slightly lowered $(18 \%)$ in the iron-deficient preparations. These results strongly suggest that the markedly lowered enzymatic activities may be due to a reduction of the nonheme iron-sulfur components of the electron transport systems, since the heme-iron components (cytochromes) were relatively unaffected by iron deficiency. As further shown in Table 1, the average weight of brown adipose tissue was not significantly different in the iron deficient and control animals.

When control and iron-deficient rats were treated with 10 daily injections intraperitoneally of $1 \mu \mathrm{g}$ of T3 before the experiments were performed, significant increases (approximately $30 \%, p<$ 0.01 ) in the amount of brown fat per $\mathrm{kg}$ body weight were found in both groups of animals as shown in Table 1, although the specific activity and activity per gram of brown fat of the enzymes concerned with electron transport were not significantly altered.

In summary, the activities of the mitochondrial electron transport systems of brown adipose tissue were markedly reduced in the iron-deficient rats. The reduced activities may have been due to depletion of the nonheme iron-sulfur components of the enzyme systems since the cytochrome components appeared to be relatively unaffected, as has been previously observed in studies of iron-deficient rat skeletal muscle $(13,14)$. The lowered activity of the mitochondrial electron transport systems represents a markedly impaired ability of the brown adipose tissue to generate heat and, therefore, may be a factor in the inability of iron-deficient rats to maintain normal cold-induced thermogenesis $(1,2)$. When iron-deficient rats were treated with daily injections of $\mathrm{T} 3$ there was a significant increase in the amount of brown fat present per kilogram of body weight and, therefore, of the capacity per kilogram of the animals to produce heat, even though the specific activities of the mitochondrial electron transport system were not affected. It has been previously shown that brown fat thermogenesis is regulated by norepinephrine and T3 [see review by Nichols (15)] and this is in accord with the published findings by Dillman et al. $(1,2)$ and Beard et al. (3) that treatment with $\mathrm{T} 3$ increased the ability of iron-deficient rats to adapt to cold temperatures. The findings of Beard et al. $(3,4)$ that transfusing iron-deficient rats restored cold resistance to normal suggests that anemia may be an important factor in the cold sensitivity of iron deficiency. However, Beard et al. (3) also found that transfusion allowed a rise in T3 levels suggesting that thyroid hormones may play a role in the improvement in cold resistance produced by transfusion.

\section{REFERENCES}

1. Dillman E, Gale C, Green W, Johnson D, Mackler B, Finch CA 1979 Abnormal thermoregulation due to an impaired $\mathrm{T} 4$ to $\mathrm{T} 3$ conversion in iron deficiency. Clin Res 27:483a

2. Dillman E, Gale C, Green W, Johnson DG, Mackler F, Finch C 1980 Hypothermia in iron deficiency due to altered T3 metabolism. Am J Physiol 239:R377-R381 
Table 2. Effects of iron deficiency on the concentrations of cytochrome pigments in mitochondria of brown adipose tissue*

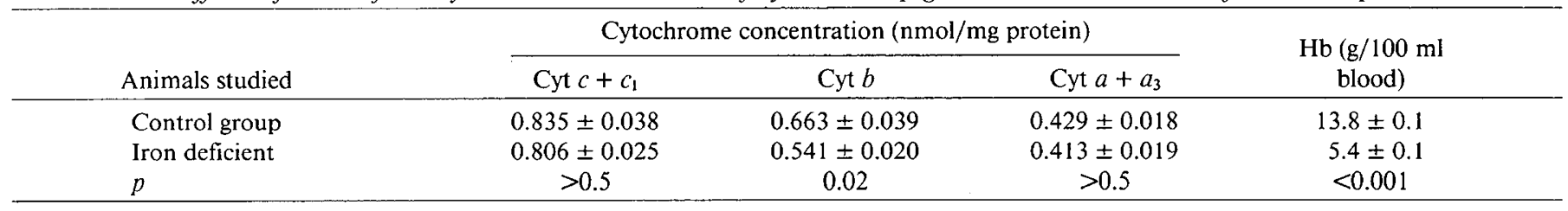

* All values represent the averages of data for 10 or more separate experiments \pm SEM.

3. Beard J, Finch CA, Green WL 1982 Interactions of iron deficiency, anemia, and thyroid hormone levels in the response of rats to cold exposure. Life Sci 30:691-697

4. Beard J, Green W, Miller LR, Finch CA 1984 Effects of iron deficiency anemia on hormone levels and thermogenesis during cold exposure. Am J Physiol 247:R114-R119

5. Foster DO, Frydman ML 1978 Nonshivering thermogenesis in the rat. II. Measurements of blood flow with microspheres point to brown adipose tissue as the dominant site of the calorigenesis induced by noradrenaline. Can J Physiol Pharmacol 56:110-122

6. Himma-Hagen J, Desautels M 1978 Amitochondrial defect in brown adipose tissue of the obese (ob/ob) mouse: reduced binding of purine nucleotides and a failure to respond to cold by an increase in binding. Biochem Biophys Res Comm 83:628-634

7. Skala J, Barnard T, Lindberg O 1970 Changes in interscapular brown adipose tissue of the rat during perinatal and early postnatal development and after cold acclimation. II. Mitochondrial changes. Comp Biochem Physiol 33:509528
8. Van Gelder BF 1966 On cytochrome $c$ oxidase: I. The extinction coefficients of cytochrome $a$ and cytochrome $a_{3}$. Biochem Biophys Acta 118:36-46

9. Chance B 1952 Spectra and reaction kinetics of respiratory pigments of homogenized and intact cells. Nature (Lond) 169:215-221

10. Chance B, Williams GR 1955 Respiratory enzymes in oxidative phosphorylation: II. Difference spectra. J Biol Chem 217:395-407

11. Lowry OH, Rosebrough NJ, Farr AL, Randall RH 1951 Protein measurements with the Folin phenol reagent. J Biol Chem 193:265-275

12. Snedecor GW, Cochran WG 1974 In: Statistical Methods, 6th ed. Iowa State University Press, Ames, IA, pp 258-298

13. Finch CA, Miller LR, Inamdar AR, Person R, Seiler K, Mackler B 1976 Iron deficiency in the rat: Physiological and biochemical studies of muscle dysfunction. J Clin Invest 58:447-453

14. Maguire JJ, Davies KJA, Dallman PR, Packer L 1982 Effects of dietary iron deficiency on iron-sulfur proteins and bioenergetic functions of skeletal muscle mitochondria. Biochim Biophys Acta 679:210-220

15. Nicholls DG 1979 Brown adipose tissue mitochondria. Biochim Biophys Acta Rev Bioenerget 549:1-29 